Saudi Journal of Oral and Dental Research

Abbreviated Key Title: Saudi J Oral Dent Res

ISSN 2518-1300 (Print) |ISSN 2518-1297 (Online)

Scholars Middle East Publishers, Dubai, United Arab Emirates

Journal homepage: https://saudijournals.com

Case Report

\title{
Factitious Introduction of a Tooth Pick Into Carious Deciduous Mandibular Molar Tooth beyond the Furcation
}

\author{
Ahlam Ahmed Ismail Shafei ${ }^{1}$, Mohammed Buhays Hussain Jarab ${ }^{2}$, Elnour Ibrahim Elbeshir ${ }^{3}$, Fareedi Mukram $\mathrm{Ali}^{4 *}$ \\ ${ }^{1}$ General Dental Practitioner, Armed Forces Hospital Southern Region, Khamis Mushait, KSA \\ ${ }^{2}$ General Dental Practitioner, Hayaty Asnani Private Clinic, Jazan, KSA \\ ${ }^{3}$ Professor, Department of Oral \& Maxillofacial Surgery, College of Dentistry, Jazan University, Al Maarefah Rd, Jazan Saudi Arabia \\ ${ }^{4}$ Assistant Professor, Department of Oral \& Maxillofacial Surgery, College of Dentistry, Jazan University, Al Maarefah Rd, Jazan Saudi Arabia
}

\begin{abstract}
DOI: $10.36348 /$ sjodr.2021.v06i01.008
| Received: 24.12.2020 | Accepted: 04.01.2021 | Published: 14.01.2021
\end{abstract}

*Corresponding author: Dr. Fareedi Mukram Ali

\section{Abstract}

Insertion or impaction of foreign objects into the tooth pulp chamber or canals by children are common findings, as they often have habit of inserting foreign objects in the oral cavity, but insertion of tooth pick is a rare finding. These foreign objects can become a potent source of infection. Retrieval of these objects from teeth is a challenging aspect of pediatric dentistry. Radiopaque foreign objects can be diagnosed in routine radiographs, which play important role in analysis of the size, location and type of foreign object, however this does not apply for radiolucent objects. The present paper describes a rare case of insertion of tooth pick into the deciduous mandibular molar tooth.

Keywords: Foreign body, Tooth pick, Deciduous tooth.

Copyright $\odot 2021$ The Author(s): This is an open-access article distributed under the terms of the Creative Commons Attribution 4.0 International License (CC BY-NC 4.0) which permits unrestricted use, distribution, and reproduction in any medium for non-commercial use provided the original author and source are credited.

\section{INTRODUCTION}

Children often have the habit of insertion of foreign objects into the mouth, and teeth especially in children undergoing root canal treatment. Some of them develop a persistent habit and when traumatized, they do not report to the parents because of fear of punishment $[1,2]$.

Lack of parental surveillance is sometimes responsible for such kind of accident as they fail to keep watch on their children and their teeth [3].

Clinical and radiographic examination with detailed case history are necessary for arriving at a conclusion regarding nature, size and location of the object; and also for the judgement regarding difficulty in removal of the foreign object $[4,5]$.

If it is confined to the pulp chamber or root canal, its removal is not very difficult. However, if it is pushed periapicaly, the procedure can become more complicated [2].
The present article describes a case of foreign body lodgment in the deciduous mandibular molar tooth in a 11 - year- old male patient.

\section{CASE REPORT}

A young boy aged 11 years complained of swelling and pain on the left side of the mandible of 8 days duration. On examination a firm swelling at left side of the mandible at the region of deciduous second molar was noted. The deciduous mandibular left second molar tooth was found carious and slightly mobile.

Exploration of the carious cavity yielded a wooden tooth pick inserted down to a level exceeding the furcation, but the patient did not admit to insertion of this tooth pick (Figures 1, 2, and 3).

The tooth pick and then the left mandibular deciduous second molar was then removed under LA and Amoxicillin 250 capsules eight-hourly was prescribed along with Pracetamol $500 \mathrm{mg}$ tablet and warm saline mouth washes. There was no need for incision and drainage as there was no fluctuation. On follow up, the patient had an uneventful recovery. 
Ahlam Ahmed Ismail Shafei et al; Saudi J Oral Dent Res, Jan 2021; 6(1): 44-46

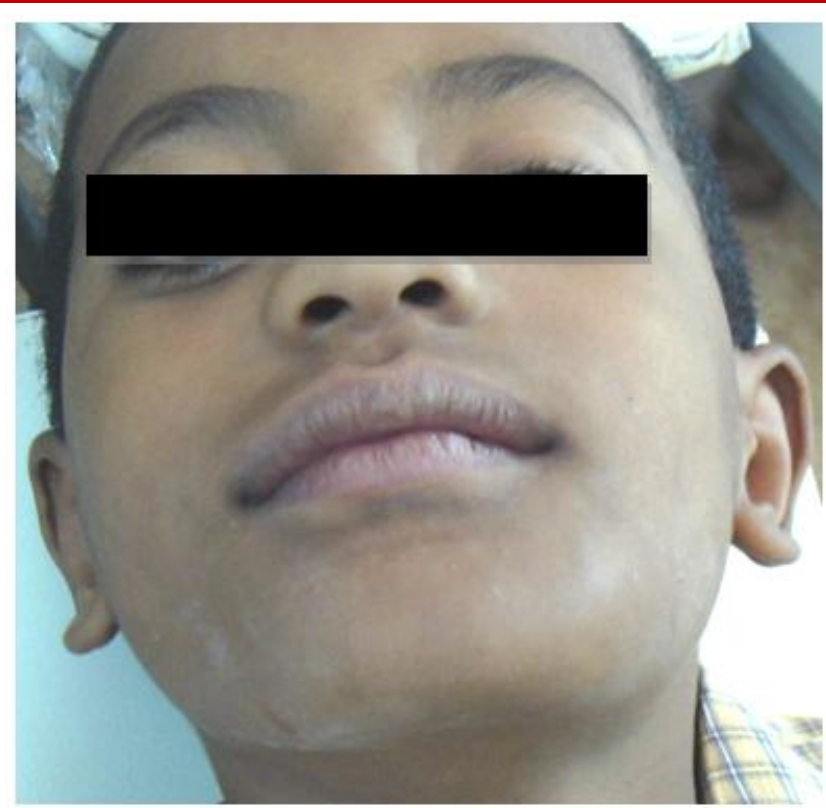

Fig-1: Showing swelling at the left mandibular molar premolar region

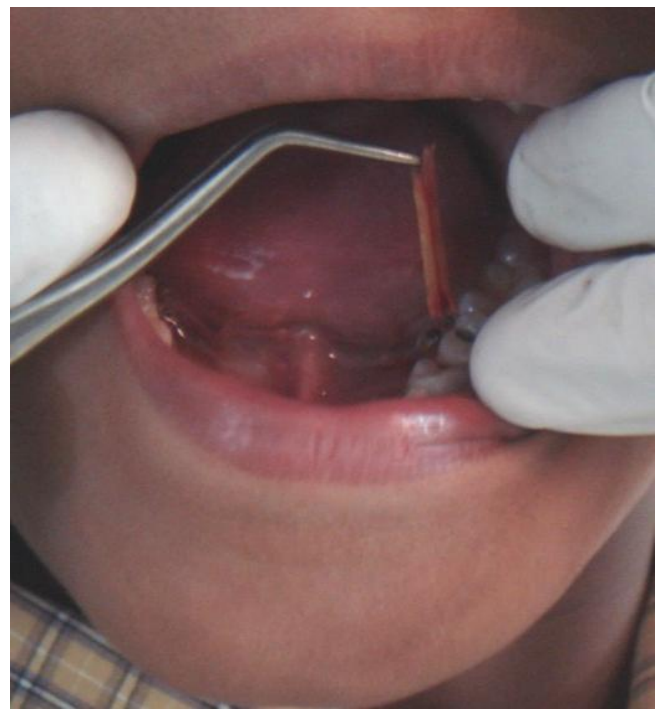

Fig-2: Showing removal of toothpick from the deciduous mandibular second molar

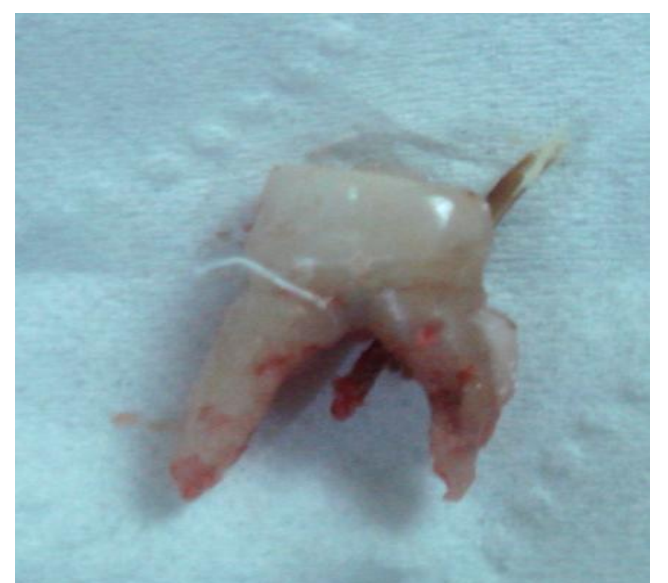

Fig-3: Showing the extracted deciduous mandibular second molar along with the toothpick

\section{DISCUSSION}

Teeth with carious lesion and having open pulp chamber and root canal, often act as a site for insertion of foreign objects. These can act a potential source of infection and sometimes leading to development of pain, swelling and abscess formation. Detailed case history, clinical and radiographic examination is necessary for detecting the cause and arriving at an appropriate diagnosis [6, 7].

Various foreign objects were reported in the literature to be lodged in the pulp chamber or root canal of deciduous or permanent teeth, like metallic paper clip, pencil lead, metal screws, stapler pins, beads, darning needle, toothpicks, ink pen tips, tomato seeds, crayons, straws, dressmaker pins, hat pins, aluminium foil, nails, sewing needle, etc [8-10].

There are numerous radiographic methods for studying the location of the foreign objects, such as Parallax views, Triangulation techniques, Stereo Radiography, Tomography, Radiovisiography and CT scans [11].

These foreign objects when inserted into tooth pulp chamber or root canal can become a focus of infection, like actinomycosis, chronic maxillary sinusitis, has been reported in the literature [8].

Various types of instruments and kits can be used for the retrieval of foreign objects from the tooth pulp chamber or root canal, like ultrasonic, endodontic forceps, endodontic files, modified Castroviejo needle holders [12], the Masserann kit [13] and Steglitz forceps, hollow tube- based extractor systems [14, 15]. The most important factor in retrieving foreign objectives and fractured instrument is the location of the fragment and its relationship with the curvature of the canal $[8,16]$.

\section{CONCLUSION}

The present paper highlights the importance of the proper diagnosis and treatment of the foreign body impaction into teeth with gross caries. Parents must be vigilant for such attempts by children and routine visits to dentist are important tonserve teeth and prevent such a mishap. Tooth pick insertion in a tooth beyond the furcation is rather unusual. The form of toothpick impaction in the tooth is unusual.

\section{REFERENCES}

1. Rangeeth, B. N., Moses, J., \& Reddy, N. V. (2011). Self-injurious behavior and foreign body entrapment in the root canal of a mandibular lateral incisor. Journal of Indian Society of Pedodontics and Preventive Dentistry, 29(6), 9598.

2. Khandelwal, D., Kalra, N., Tyagi, R., \& Khatri, A. (2019). Accidental diagnosis of a foreign body 
embedded in maxillary anterior tooth. Journal of the Scientific Society, 46(3), 103-105.

3. Kariya, P. B., Singh, S., Mallikarjuna, R. M., \& Govil, S. (2016). Dental neglect leading to foreign body lodgement in pulp chamber. Advances in Human Biology, 6(3), 145-148.

4. Buckley, S. B., Odinet, K. A., \& Van Sickels, J. E. (1984). Foreign body in tongue: clinical report. Pediatric Dentistry, 6(2):107-108.

5. Dhull, K. S., Acharya, S., Ray, P., \& Dhull, R. S. (2013). Foreign body in root canals of two adjacent deciduous molars: a case report. International journal of clinical pediatric dentistry, 6(1), 38-39.

6. Ashqar, N. M., \& Ali, F. M. (2019). Unusual foreign object in a tooth: A case report and review of literature. Clinics and Practice, 9(1):11-14.

7. Sharmin, D. D., Sistla, S., \& Gunasekaran, R. (2017). Unusual foreign objects in the teeth-a case report. J Dent Oral Disorder Ther, 5(3):1-2.

8. Alrahabi, M., \& Gabban, H. (2014). Management of foreign object in the root canal of central incisor tooth. Saudi Endodontic Journal, 4(3), 154-157.

9. Passi S, Sharma N. Unusual Foreign Bodies in the Orofacial Region. Case Reports in Dentistry, 2012, Article ID 191873, 4 pages.

10. Katge, F., Mithiborwala, S., \& Pammi, T. (2013). Incidental radiographic discovery of a screw in a primary molar: an unusual case report in a 6 year old child. Case reports in dentistry, 2013.

11. Kanumuri, P. K., Gantha, S. N., Animireddy, D., \& Chinta, M. (2016). Unusual foreign body in primary tooth. Case Reports, 2016, 1-2.

12. Ward, J. R., Parashos, P., \& Messer, H. H. (2003). Evaluation of an ultrasonic technique to remove fractured rotary nickel-titanium endodontic instruments from root canals: clinical cases. Journal of Endodontics, 29(11), 764-767.

13. Cheung, G. S. (2007). Instrument fracture: mechanisms, removal of fragments, and clinical outcomes. Endodontic Topics, 16(1), 1-26.

14. Roda, R. S., \& Gettleman, B. H. (2011). Nonsurgical Retreatment in Cohen's Pathways of the Pulp. 10th ed. St. Louis, Missouri: Elsevier Mosby. 901-910.

15. Ward, J. R., Parashos, P., \& Messer, H. H. (2003). Evaluation of an ultrasonic technique to remove fractured rotary nickel-titanium endodontic instruments from root canals: an experimental study. Journal of Endodontics, 29(11), 756-763.

16. Fors, U. G. H., \& Berg, J. O. (1983). A method for the removal of broken endodontic instruments from root canals. Journal of endodontics, 9(4), 156-159. 